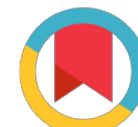

Check for updates
*For correspondence:

mhlee@mdanderson.org

Competing interests: The authors declare that no competing interests exist.

Received: 2017-04-30

Accepted: 2017-05-29

Published: 2017-09-05

Copyright The Author(s) 2017. This article is published with open access by BioMedPress (BMP).

This article is distributed under the terms of the Creative Commons Attribution License (CC-BY 4.0) which permits any use, distribution, and reproduction in any medium, provided the original author(s) and the source are credited.

\section{COP9 signalosome in regulating EGFR oncogenic signals}

\author{
Lekun Fang, Bo Chen, Hyun-Ho Choi, Ji-Hyun-Shin,Liem Phan, Sai-Ching J \\ Yeung, Mong-Hong Lee
}

Department of Molecular and Cellular Oncology, The University of Texas M.D. Anderson Cancer Center, 1515 Holcombe Blvd. Houston, TX 77030

USA

\section{Abstract}

The constitutive photomorphogenesis 9 signalosome (CSN) regulates the stability of tumor suppressor and oncogenic proteins via proteasome-mediated protein degradation. The detailed regulatory mechanisms of CSN subunit expression in tumorigenesis remain to be illustrated. We demonstrated several important biological functions of CSN6: p53 signal transduction, neddylation regulation of Cullin, F-box protein ubiquitination, and Myc stability regulation. Biochemical studies demonstrated that CSN6 is involved in cell cycle regulator stability function and various cancer signaling pathways, including epidermal growth factor receptor (EGFR) pathway. We show that CSN6 overexpression is frequently observed in human colorectal cancers, which leads to drug resistance in anti-EGFR treatment and is correlated with poor clinical survival. We present amechanism for the role of CSN6 in ERK signaling cascade and provide new insights into the functional role of CSN6 deregulation during tumorigenesis.

\section{Keywords}

ERK CSN, neddylation Myc, ubiquitination, colorectal cancer

\section{Funding}

\section{References}

